\title{
Forecast calls for clouds over biological computing
}

The reams of genomic and proteomic data produced from high-throughput analyses promise to answer some of the toughest questions in medicine. But the flood of information from today's experiments might be too much of a good thing-most universities and biotech companies lack the necessary computing infrastructure to store and use it. To boost their computer power, many researchers are starting to look beyond the walls of their institutions and turning toward a new decentralized computer platform.

In the past, researchers who sought highperformance computing needed access to either a supercomputer or a grid of many smaller machines working together. Now, scientists can take advantage of the Internet to upload and analyze data. The approach, called cloud computing, provides access to near-limitless processing and storage capacity on a pay-as-you-go basis. "Cloud [computing] promises wholly new capabilities of almost instant availability and of massive scale," says Sanjoy Ray, director of technology innovation at Merck Research Laboratories in New Jersey.

Large pharmaceutical companies have been some of the first to adopt the new technology. In 2007, a team at Eli Lilly in Indianapolis started using a cloud computing platform developed by Amazon Web Services, a division of the online retail giant Amazon.com, for a range of tasks, including biomarker investigations and analysis of small molecules docking with proteins.

Johnson \& Johnson Pharmaceutical Research and Development in Raritan, New Jersey also began experimenting with cloud computing in 2008, despite already boasting some of the most considerable computing power in the business. "We have a pretty large grid infrastructure," says Rick Franckowiak, director of systems engineering at Johnson \& Johnson. Still, the company's peak computer needs often outstrip in-house capacity. That's a perfect situation for going into the cloud.

Academic researchers are also putting cloud computing to good use. For example, in November, Arie Meir and Boris Rubinsky, biomedical engineers at Hebrew University in Jerusalem, used cloud computing to turn data from a two-dimensional ultrasound device into three-dimensional scans (PloS ONE 4, e7974; 2009.)

Still, Geoffrey Fox, a computer scientist at Indiana University in Bloomington, cautions that cloud computing alone can't solve all the problems associated with oodles of data. "The use of clouds is easy, but it is not so easy to get good performance," says Fox, who is investigating new algorithms for analyzing next-generation DNA sequence data with clouds.

\section{Top 10 pharma firings of 2009}

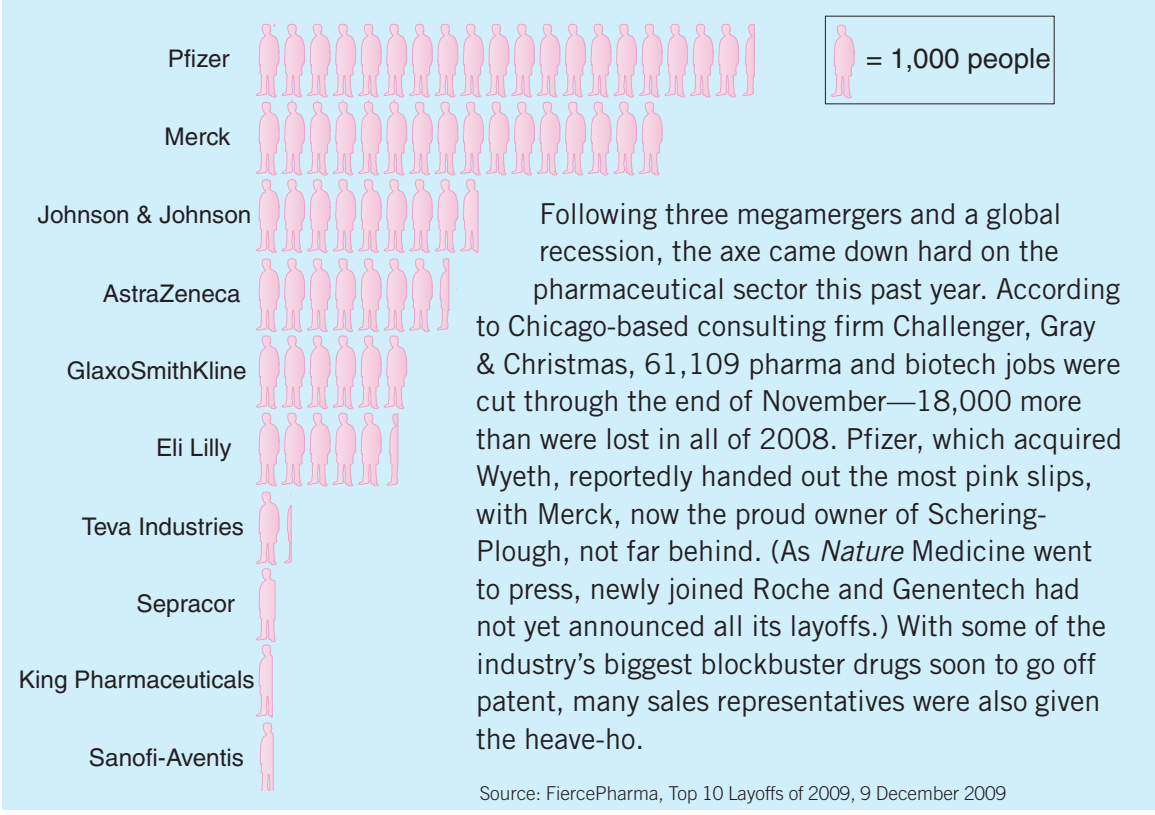

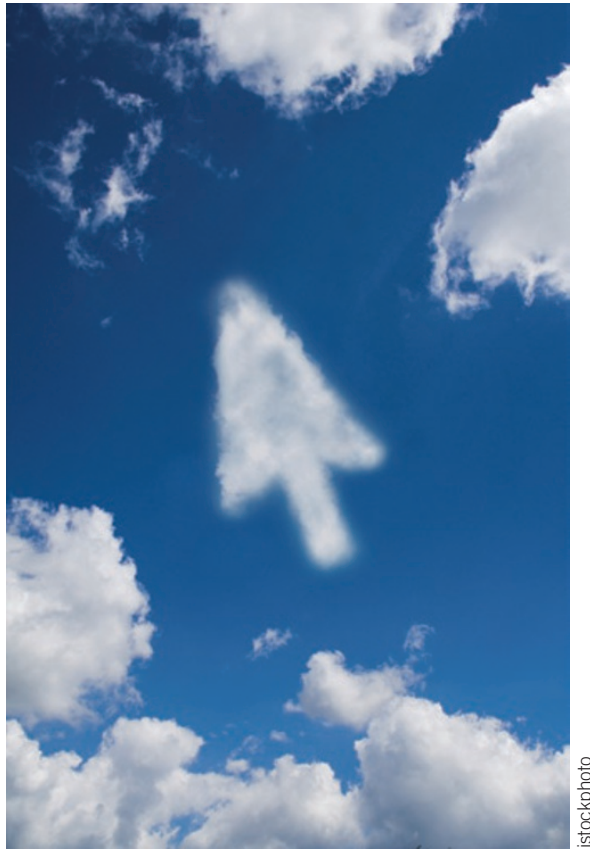

Cloud nine: Internet computing improves analyses

Despite the power of cloud computing, concerns abound over the technology's security, as users tend to rely on commercial clouds, such as those offered by Amazon and Yahoo. To prevent data theft, researchers at Eli Lilly usually chop up data into pieces and distribute it on different cloud systems, says information analyst Dave Powers. Powers likens the approach to mixing up jigsaw puzzles - if hackers find one 'piece' of data, they still can't assemble the whole 'puzzle'. For many users, however, cloud computing offers enhanced data protection. "Security on Amazon's cloud is better than most lab security," says Robert Grossman, director of the University of Illinois at Chicago's Laboratory for Advanced Computing, which completed a private cloud in 2008.

Despite some early successes, most of the technology's proponents agree that the key cloud applications lie in the future, when researchers start to compare whole genome sequences and phenotypic data from millions of people. "Ten years from now," says Rudolph Tanzi, a geneticist at Massachusetts General Hospital in Boston, "it's not unreasonable to think that we'll need yottabytes" $-10^{24}$ bytes or a quadrillion gigabytes_ “of data." To enable such storage capacity, Tanzi urges the federal government to build a public cloud that will lay the foundation for the future of personalized medicine.

Mike May, Houston 